\title{
Family income and child health in the UK
}

\author{
Bénédicte Apouey $^{a}$, Pierre-Yves Geoffard ${ }^{b}$
}

March 1, 2012

${ }^{a}$ CEPREMAP, 48, Boulevard Jourdan, 75014 Paris, France, and Department of Economics, University of South Florida, 4202 East Fowler Avenue, BSN 3403, Tampa, Florida 33620-5500, USA.

E-mail address: benedicte.apouey@gmail.com.

${ }^{b}$ Paris School of Economics, 48, Boulevard Jourdan, 75014 Paris, France.

E-mail address: geoffard@pse.ens.fr.

\section{Please do not quote or circulate or publish on the internet.}

Send all correspondence to:

Bénédicte Apouey

Department of Economics

University of South Florida

4202 East Fowler Avenue, BSN 3403

Tampa, Florida 33620-5500

USA.

Voice: 00-1-813-974-0461.

Fax: 00-1-813-974-6510.

E-mail: benedicte.apouey@gmail.com. 


\begin{abstract}
Recent studies examining the relationship between family income and child health in the UK have produced mixed findings. We re-examine the income gradient in child general health and its evolution with child age in this country, using a very large sample of British children. We find that there is no correlation between income and child general health at ages $0-1$, that the gradient emerges around age 2 and remains constant from ages 2 to 17 . In addition, we show that the gradient is likely to represent a causal effect of income on child health. Furthermore, we suggest that the gradient in general health reflects a greater prevalence of chronic conditions among low-income children and a greater severity of these conditions. Taken together, these results suggest that income does matter for child health in the UK and may play a role in the intergenerational transmission of socioeconomic status.
\end{abstract}

JEL classification: I1

Keywords: Child health; Family income; Gradient

\title{
Acknowledgements
}

Data from the FACS were supplied by the ESRC Data Archive. Neither the original collectors of the data nor the Archive bear any responsibility for the analysis or interpretations presented here. We would like to thank Hugh Gravelle, Gabriel Picone, Jennifer Stewart, Michael Wolfson and participants to the Health Economics seminar at the University of South Florida (2011), the 45th Annual Conference of the Canadian Economics Association (2011) and the CES-HESG workshop in Aix-en-Provence (2012) for their constructive comments. 


\section{Introduction}

A large amount of literature shows a positive correlation between socioeconomic status and health in adulthood (Adler et al., 1994; Deaton and Paxson, 1998; Deaton and Paxson, 1999; Van Doorslaer et al., 1997; Wilkinson and Marmot, 2003). Recent research initiated by Case et al. (2002) investigates whether the gradient in general health observed in adulthood has antecedents in childhood. Understanding the determinants of child health is important because health in childhood affects human capital accumulation, and health and labor market status in adulthood (Currie, 2008). Findings firmly establish that family income is positively related to children's general health in Australia (Khanam et al., 2009), Canada (Currie and Stabile, 2003), Germany (Reinhold and Jurges, 2011) and the US (Case et al., 2002; Condliffe and Link, 2008). Moreover, the correlation between family income and children's general health strengthens as children grow older in Canada and the US, meaning that the disadvantages associated with parental income accumulate as children age (Case et al., 2002; Currie and Stabile, 2003). These authors argue that the steepening of the gradient with age can be due to two mechanisms: (1) either children from poorer families are more likely to be subject to health shocks than their wealthier counterparts (prevalence effect), or (2) poorer children are less able to respond to health shocks, and so health shocks are more severe for them (severity effect). The distinction between these two mechanisms is important because they have different implications from a policy perspective: the first mechanism implies that the gradient may be reduced by addressing the reasons why poorer children are more likely to get chronic conditions, whereas the second mechanism means that a policy should improve access to palliative care for poorer children. In the US, the strengthening of the gradient is due to a combination of the prevalence and severity effects (Case et al., 2002), whereas in Canada, it is only due to the prevalence effect (Currie and Stabile, 2003).

Findings on the gradient in general health for British children are not firmly established. Currie et al. (2007) and Case et al. (2008) analyze the evolution of the gradient as children grow older, using cross-sectional data from the Health Survey for England (HSE), the same variables and the same methods. Specifically, they estimate the gradient for four age groups (children ages 0-3, 4-8, 9-12, 13-17) and compare the estimates between the age groups to depict the evolution of the gradient with age. In spite of these similarities, their conclusions are different. Currie et al. (2007) highlight that there is a gradient in general 
health, that it increases between 0-3 and 4-8 and stops increasing afterwards, using six waves of the HSE. In contrast, Case et al. (2008) conclude that the gradient in general health does increase with age from birth to age 12, using three additional years of data from the HSE. In addition, Propper et al. (2007) suggest that when maternal health and behaviors are included, there is almost no correlation between family income and child health, for a cohort of British children less than 7 years of age. This means that the gradient may not reflect any causal effect of family income on child health.

The previous literature on the UK uses relatively small datasets, which could explain why the results are somewhat contradictory. A larger sample of British children may shed more light on the gradient in general health. In addition, the previous literature on the UK investigates the evolution of the gradient in general health using four age groups, which makes it impossible to examine the turning points in the evolution of the gradient with age. We suggest to compare the gradient between ages, instead of age groups, to get a precise description of the evolution of the general health/income relationship with age. Finally, in a small sample like the HSE, it is not possible to study the role of rare chronic conditions in the general health gradient: the analysis of rare chronic conditions requires large sample sizes.

This paper re-examines the general health/income gradient in childhood in the UK, using a large sample of approximately 78,000 children drawn from the Family and Children Survey (FACS). First, we exploit the large sample size of the FACS to investigate the evolution of the gradient with child age in a more detailed manner. Specifically, we estimate the effect of income on health separately for children of each age, instead of each age group. Second, we examine whether the association between family income and child health represents causation running from income to child health, as opposed to reverse causation or the omission of third factors. We adopt two strategies. On the one hand, we take advantage of the information we have on the influence of child health on family income in the FACS, to eliminate reverse causation. As far as we are aware, we are the first to deal with this issue in a precise manner. On the other hand, we expand on the number of controls to address the omission of factors. Third, we examine the role of specific health problems, in particular some rare chronic conditions, Special Educational Needs and the attention deficit hyperactivity disorder (ADHD), in the gradient in general health. This focus represents an innovation for a study on the UK. Fourth, we investigate the channels through which family income could have an impact on child health, focusing on housing 
conditions, nutrition and outfit.

We find that there is a very small or negligible effect of family income on general health for children ages 0-1 and a large and significant effect for children above 2. In addition, the gradient remains constant as children grow older, from ages 2 to 17 . This description of the gradient is very different from that given in the earlier literature on the UK, which highlights an increase in the gradient with age between birth and age 12 . We also show that our results are robust to various procedures that address the endogeneity of income. This finding also contrasts with previous results that suggest that there is no causal effect of family income on child health. The paper also finds that the gradient in general health could be explained both by the prevalence and severity of specific health problems among low-income children, which implies that policies should address the reasons why lowincome children are more likely to obtain specific health problems and why the severity of these specific problems depends on income. Finally, we show that the effect of family income on child health is not accounted for by differences in housing conditions, nutrition and outfit between low and high-income children. However, housing conditions, nutrition and outfit do have a large independent effect on child general health.

The rest of the paper proceeds as follows. In Section 2, we begin by discussing the contributions of the previous literature and highlight the originality of our approach. Section 3 provides an overview of the data. Section 4 investigates in details the evolution of the gradient and discusses the endogeneity of income. Section 5 focuses on the role of specific health problems in the gradient in general health. Section 6 examines whether housing conditions, nutrition and outfit are important channels through which family income influences child health. Lastly, Section 7 offers some concluding remarks.

\section{Background}

\subsection{Previous research}

We first briefly present the previous literature, focusing on the four aspects of the gradient that we are interested in: whether there is a correlation between income and child general health, whether this correlation changes with child age, whether the gradient represents a causal effect of income on general health and whether specific health problems, such as chronic conditions, play a role in the gradient in general health. 


\section{Developed countries other than the UK}

Case et al. (2002) show that child general health is positively related to family income and that this relationship becomes more pronounced as children grow older in the US, using cross-sectional data from the National Health Interview Survey. Interestingly, the gradient probably reflects a causal effect of family income on child general health in the US.

Currie and Stabile (2003) demonstrate that the results of Case et al. (2002) also hold in Canada. In addition, they provide evidence that the gradient increases with age because low-income children are more likely to be subject of health shocks.

Khanam et al. (2009) investigate the gradient in Australia, using the first two waves of the Longitudinal Study of Australian Children. They find that there is a gradient that strengthens with age, when similar covariates to Case et al. (2002) are included. However, when they include richer sets of controls to address the endogeneity of income, the gradient disappears. These results suggest that in Australia, the gradient does not reflect any causal effect of income on health but the omission of factors.

Finally, Reinhold and Jurges (2011) show that the gradient in Germany is as strong as in the US but that the disadvantages associated with parental income do not accumulate as children grow older.

\section{The UK}

In contrast with the clear findings for other developed countries, previous results on the gradient in general health in the UK are not firmly established. Patrick West argues that there is a strong socioeconomic gradient in childhood, but that it decreases or virtually disappears in youth, i.e from age 12. Youth would be a period of relative equality in health with respect to self-rated health (West, 1988), mortality, symptoms of acute illness, nonfatal accidents and injuries (West, 1988, 1997). West's approach is mainly descriptive and it raises the question of the extent to which the association between socioeconomic status and child health reflects a causal effect of socioeconomic status as opposed to the endogeneity of socioeconomic status. Our paper provides an answer to that question.

Currie et al. (2007) and Case et al. (2008) also explore the evolution of the gradient with age, in an econometric framework. These two papers use similar approaches but draw different conclusions. They both use cross-sectional data from the Health Survey for England (HSE) and examine the gradient using four age groups: children ages 0-3, 4-8, 9- 
12 and 13-15. The authors quantify the gradient for each of these age groups and compare the gradient estimates between the groups, to depict the evolution of the gradient with age. Currie et al. (2007) use data from the 1997-2002 HSE, which corresponds to approximately 14,000 children. They find a significant family income gradient in child general health, but they do not observe any strengthening of the gradient with age. Case et al. (2008) re-examine these findings using the same method and variables but an expanded sample from the HSE, by adding three years of data, which corresponds to approximately 20,000 children. In contrast with Currie et al. (2007), they conclude that the income-general health gradient increases with age between birth and age 12. In spite of their similarities, the papers by Currie et al. (2007) and Case et al. (2008) reach different conclusions. We think that a larger dataset might help get more stable results. In addition, these two papers use four age groups, which makes it impossible to get a precise description of the evolution of the gradient with age. Knowing at which age the gradient strengthens is important because it indicates the optimal age at which policies aimed at reducing social inequalities in health should be implemented. In this perspective, we suggest examining the evolution of the gradient between ages, instead of age groups.

Kruk (2010) analyze the role of chronic conditions in the gradient in general health. She investigates whether poor children are more likely to obtain chronic conditions (prevalence effect) and whether chronic conditions are more severe for poor children (severity effects). Kruk (2010) uses the first three waves of the Millennium Cohort Study (MCS), which corresponds to approximately 13,000 children less than 6 . She examines the prevalence effect for children ages 2-3 (wave 2) and 5-6 (wave 3) and the severity effect for children ages 5-6 (wave 3). She shows that there are both a prevalence and a severity effect for young British children. However, as pointed out by Case et al. (2008), it is not possible to get precise estimates of the role of rare chronic conditions with small sample sizes. Our paper tries to fill this gap in the literature.

Following Burgess et al. (2004), Propper et al. (2007) investigate whether the gradient represents a causal effect of income on health. They use data from the Avon Longitudinal Study of Parents and Children (ALSPAC), which contains from 4,000 to 11,000 children (depending on specifications) below 7 years of age. When basic sets of controls are included, the authors find a positive correlation between family income and child health, but no evidence of an increase of the gradient between birth and age 7 . To address the endogeneity of income, they then expand the number of controls. When they include 
parental behaviors and health, the gradient almost disappears. This finding thus casts doubts on the existence of a causal effect of family income on child health. It also raises the question of whether this result also holds for children above 7 and for a larger sample of children. Our paper provides precise answers to these questions.

\subsection{Our approach}

In this article, we use the Families and Children Study (FACS) to explore the effect of income on health in the UK. These data have a number of interesting characteristics compared to the ALSPAC, MCS and HSE used in the previous literature. Table 1 presents a brief comparison of the FACS data with these datasets. First, the sample size of the FACS is much larger, for each age. Second, the FACS contains children of all ages, from 0 to 17 . Third, parents always report their children's health, whatever their age is, so the child general health measure is consistent across ages, unlike in the HSE. Fourth, household members report their exact income level and not income in brackets, which reduces measurement error in the income variable. Fifth, the FACS data are longitudinal and we could thus compute the average income for each household. Average income is less likely to be measured with error than current income. Taken together, these characteristics of the data enable us to get more precise estimates of the child health/income gradient than the previous literature.

[Insert Table 1 here]

In this paper, we exploit the large sample size of the FACS to investigate the existence and evolution of the gradient in childhood. Specifically, we estimate the gradient in general health at each age, instead of each age group.

We also explore the extent to which the correlation between family income and child general health represents a causal effect of income on health, as opposed to reverse causation and the omission of third factors. To do that, we take advantage of the FACS data and eliminate from the sample the households for which we suspect a causal effect running from child health to family income. As far as we are aware, this constitutes an originality of this paper. In addition, to address the omission of third factors, we estimate augmented models in which we include a large number of controls (Case et al., 2002; Khanam et al., 2009; Propper et al, 2007). 
We also analyze the role of specific health problems in the gradient in general health, focusing on the role of chronic conditions (including some rare conditions), Special Educational Needs and ADHD. This focus represents an innovation for a study on the UK (Currie and Lin, 2007). We investigate whether low-income children are more likely to obtain specific health problems and whether these specific problems are more detrimental to their general health.

Finally, the paper investigates whether housing conditions, nutrition and outfit are channels through which family income translates into better child health.

\section{The data}

We use the 2001-2008 FACS to investigate the gradient in childhood in the UK. The FACS was formerly known as the Survey of Low Income Families, which started in 1999. It originally provided a new baseline survey of Britain's lone-parent families and lowincome couples with dependent children. Starting 2001, the survey was extended to include higher-income families, thereby yielding a complete sample of all British families (and the subsequent name change). We use all the available years of data from 2001. The data is a short panel with respondents being re-interviewed in subsequent waves. We focus on children who are dependent and who do not work. After elimination of missing values, the sample contains 78,541 observations.

Child good general health

Our main dependent variable is the general health of the child. It is generated by asking the respondent (who is generally the mother or the father of the child):

"(Since your baby was born/over the last 12 months) would you say (child's name) health has been good, fairly good or not good?"

For our analyses, we use a dichotomous variable that equals one if the child is in good health and 0 otherwise.

Child specific health problems: Chronic conditions, Special Educational Needs and ADHD

The FACS also contains information on whether the child has the following health problems, long-standing illnesses or disabilities: 1) Problem with arms, legs, hands, feet, back or neck; 2) Difficulty in seeing; 3) Difficulty in hearing; 4) Skin conditions, allergies; 5) Chest, breathing problem, asthma, bronchitis; 6) Heart, blood pressure or blood 
circulation problems; 7) Stomach, liver, kidney or digestive problems; 8) Diabetes; 9) Depression, bad nerves; 10) Mental illness, phobia, panics or other nervous problems; 11) Learning difficulties (or mental handicap); 12) Epilepsy; 13) Child congenital conditions; 14) Other health problems or disabilities. Most of these problems can be considered as chronic health conditions. We use a dummy variable for whether the child has any these chronic conditions and a series of dummy variables for whether the child has each of these conditions (except for the ones that are too rare in our sample).

Information is also collected on whether the child was identified at school as having Special Educational Needs. This is a good indicator of child health, since the reason for being identified as having these needs are typically dyslexia, dyscalculia, dyspraxia and ADHD. For our analyses, we also break out ADHD separately.

The mother's and father's health

The data contain the same health variables for the respondent and his partner. Using this information, we can find the mother and father's general health and chronic conditions. We also use information on whether the mother smokes.

\section{$\underline{\text { Income }}$}

The data contain a variable for the weekly income of the family in pounds, we adjust it using the $2005 \mathrm{CPI}$. Income is likely to be measured with error, which may bias our results. To reduce the measurement error, we average income over all the available years, provided that there are at least two years of data. In most of our estimations, we take the logarithm of average income, to account for the non-linearity in the health/income relationship.

Summary statistics for the analysis sample are in Table 2.

\section{[Insert Table 2 here]}

\section{First description of the gradient}

We first present evidence on the relationship between average family income and child general health, in the absence of any control. Figure 1 shows the probability that the child is in good health as a function of average family income, separately for children of each age. For children ages 0 and 1 , there is no clear evidence that high-income children are healthier than low-income children. In contrast, for children above 2 , the figures exhibit a positive income gradient. This gradient seems to remain constant with child age: we 
neither observe a strengthening nor a vanishing of the gradient as children grow older. This result contrasts with findings by West (1997) who shows using the 1991 British Census, that the gradient, which is strong until age 10, diminishes or vanishes for adolescents ages 11-19. Our findings also differ from previous results for the US which highlight a steepening of the gradient with child age (Case et al., 2002).

[Insert Figure 1 here]

\section{The child general health/family income gradient}

\subsection{A precise description of the gradient}

The correlation between income and health we have just highlighted could be due to the omission of parental, household and child-specific characteristics. To address this concern, we run models that control for these characteristics. We examine both the existence of the income gradient and its evolution with age. Compared to the previous literature, we investigate these issues in a more precise manner, by separately analyzing children of each age, instead of each age group.

First, we examine the existence of the income gradient at each age, by estimating the following linear probability model:

$$
\begin{aligned}
G= & \alpha+\beta_{0} \operatorname{Ln}(\text { average income }) \times \text { Age } 0+\beta_{1} \operatorname{Ln}(\text { average income }) \times \text { Age } 1 \\
& +\ldots+\beta_{17} \operatorname{Ln}(\text { average income }) \times \text { Age } 17 \\
& +X \gamma+\epsilon
\end{aligned}
$$

where $G$ is a dummy indicating that the child is in good general health, Ln(average income)× Age $k$ represents an interaction term between the logarithm of average income and age $k$, which equals the logarithm of average income if the child is $k$ years old, and zero otherwise, $X$ is a set of controls and $\epsilon$ is the error term.

The estimates of $\beta_{0}, \ldots \beta_{17}$ and their confidence intervals give information on the existence of the gradient at each age: there is an income gradient in general health at age $k$ if the lower bond of the confidence interval of $\beta_{k}$ is greater than zero. 
Second, we analyze the evolution of the gradient with age, by estimating:

$$
\begin{aligned}
G= & \alpha+\chi \operatorname{Ln}(\text { average income }) \\
& +\delta_{1} \operatorname{Ln}(\text { average income }) \times \text { Age } 1+\delta_{2} \operatorname{Ln}(\text { average income }) \times \text { Age } 2 \\
& +\ldots+\delta_{17} \operatorname{Ln}(\text { average income }) \times \text { Age } 17 \\
& +X \gamma+\epsilon
\end{aligned}
$$

In this equation, the effect of income on child health at age zero is the reference. The gradient at age $k$ is significantly larger than the gradient at age zero if the lower bond of the confidence interval of $\delta_{k}$ is greater than zero.

Equations (1) and (2) are estimated using two different sets of regressors $X$, as in the previous literature (Case et al., 2002). The first set of regressors, "controls 1", includes a complete set of age and year dummies, the logarithm of household size, indicators for whether the respondent is white, the child has a mother in the household, has a father in the household and is male. The second set of regressors, "controls 2", contains the first set of controls plus interaction terms between the mother's and the father's presence in the household and their education level and employment status. With the exception of the set of age dummies, all the controls are interacted with age dummies, to account for the possibility that they have different effects on child general health over childhood years.

Panels $\mathrm{A}$ and $\mathrm{B}$ in Figure 2 represent the coefficients $\beta_{0}, \ldots \beta_{17}$ on the left graphs, and $\delta_{1}, \ldots \delta_{17}$, on the right graphs, as a function of age, their $90 \%$ confidence intervals and a nonparametric smoothing.

Figure 2, Panel A, graphs the results when "controls 1" are included. The top left graph indicates that the income gradient is significant at each age, except age 1 . The graph also suggests that the gradient is either null or small at ages 0 and 1 , that it increases between ages 1 and 3 and remains stable for children above 3 . The top right graph shows that the gradient at ages 1 and 2 is not significantly different from the gradient at age 0 , but that the gradient above 3 is significantly larger than at age 0 .

Figure 2, Panel B, represents the coefficients of interest as a function of age, when additional controls for parental education and employment are included ("controls 2"). Comparing the left graph in Panel B with the left graph in Panel A indicates that the inclusion of these additional controls reduces the size of the gradient. However, the gradient is still significant for children of all ages when "controls 2" are included, except for ages 


\section{$0,1,2,9$ and 10 .}

In Panel B, the confidence intervals of the estimated coefficients are large, which means that the coefficients are not precisely estimated. To improve the quality of the estimates, we re-run equations (1) and (2) using nine age groups, for children ages 0-1, 2-3, 4-5, 6-7, 8-9, 10-11, 12-13, 14-15 and 16-17. The new estimates on the interaction terms between income and these age groups are reported in Panel C. The left graph in Panel C shows that the gradient is significant at all ages, except at ages 0-1. The right graph in Panel $\mathrm{C}$ provides some evidence of an emergence of the gradient in early childhood between 0 and 2. In addition, both graphs in Panel $\mathrm{C}$ suggest that the gradient is stable from ages 2 to 17. These findings contrast with those from the previous literature on the UK and other developed countries: Case et al. (2008) find that the gradient strengthens from birth to age 12 in the UK, using a smaller sample of British children and four age groups, whereas Case et al. (2002) and Currie and Stabile (2003) provide evidence of a continuous increase of the gradient from birth to age 17, in the US and Canada.

\section{[Insert Figure 2 here]}

\subsection{The endogeneity of income}

A key question is the extent to which the gradient we have just estimated represents a causal effect of income on child health as opposed to the endogeneity of income. This section examines the existence of the gradient for the whole sample, the existence of the gradient at each age and the evolution of the gradient across ages, when accounting for the endogeneity of income. We address the two sources of the endogeneity of income: reverse causation and the omission of third factors.

First, our previous estimates are biased by reverse causation if child health has an effect on family income, for instance if parents do not work or reduce their work hours because of their child health or if the household receives an allowance because of child disability. To contain reverse causation, we restrict the sample to households in which there is no child whose health influences family income. Specifically, we eliminate from the analysis sample households in which at least one of the children's health prevents their parents from doing a paid job or from working as many hours as they would do otherwise, ${ }^{1}$ from looking for a job of 16 or more hours a week, and households who receive a disability living allowance

\footnotetext{
${ }^{1}$ This piece of information is available from 2004 in the data.
} 
(care or mobility) for a child. ${ }^{2}$ In total, we drop more than 10,000 observations.

In addition, the estimates of the gradient presented above do not represent the causal effect of income on child health if important third factors are omitted. To address this issue, we expand the number of regressors and include controls for British regions and for the parents' health. Indeed, articles by Khanam et al. (2009) and Propper et al. (2007) suggest that parents' health is an important determinant of child health, whose omission biases the gradient estimates.

The results are presented in Table 3. Column (1) contains the estimate of the income gradient, before the elimination of reverse causation, when "controls 2" are included. Column (2) contains the estimate of the gradient, when there is no reverse causation, and when "controls 2" are included. Comparing columns (1) and (2) suggests that the bias in the gradient estimate due to reverse causation is small. In columns (3) and (4), we expand the number of controls to address the omission of factors. When we include controls for the regions and the mother's health ("controls 3") in column (3), the coefficient on income decreases but remains very large and significant. This means that in the FACS, the correlation between family income and child health is not due to the omission of controls for the mother's health.

The estimates also suggest that the effect of the mother's health on child health is important; this is especially true for maternal mental problems. These findings confirm previous conclusions by Propper et al. (2007).

The inclusion of the father's health in column (4) has a small impact on the coefficient on income, which means that the effect of the father's health on child health is almost independent of the effect of income.

The inclusion of the father's health implies a large reduction of the sample size, because the father's health variables have many missing values. In addition, the inclusion of father's health has a small effect on the correlation between income and health. For these two reasons, we will not include the father's health in the models presented in the rest of the paper.

[Insert Table 3 here]

In further analysis, we investigate the existence of the gradient at each age and its evolution with child age, when addressing the endogeneity of income. Specifically, we

\footnotetext{
${ }^{2}$ This piece of information is available from 2004 in the data.
} 
eliminate reverse causation and then re-estimate equations (1) and (2), including either "controls 2" or "controls 3". Figures 3 and 4 display the new estimates of the interaction terms between income and age, as a function of child age.

Findings from Figures 3 and 4 support previous results presented in Figure 2. First, Figure 4, Panel B, indicates that when controls for maternal health are included, there is a positive and significant gradient in childhood, except for infants ages 0 and 1 . This results contrasts with the conclusions of Propper et al. (2007) for the UK and Khanam et al. (2009) for Australia, who observe that the gradient (almost) disappears when maternal health is included, for young children ages 0-7. Second, regarding the evolution of the gradient with age, Figures 3 and 4 provide some evidence of an emergence of the gradient between ages 0 and 2 and prove that the gradient is stable between ages 2 to 17 .

[Insert Figures 3 and 4 here]

\subsection{Robustness checks}

We check the robustness of our findings on the existence and stability of the gradient between ages 2 and 17 using other specifications. More precisely, we use either the dichotomous general health variable (Good health vs Fairly good and Not good) or the general health variable with three categories (Not good, Fairly good, Good). We estimate the gradient for each age separately using 18 distinct models, using simple and ordered probit models. Supporting our previous findings, the results indicate that there is a positive and significant income gradient from ages 2 to 17 .

In (ordered) probit models, it is not possible to test the evolution of the gradient with age by including a complete set of interaction terms between income and age, and examining their sign (Ai and Norton, 2003). In these non-linear models, testing the evolution of the gradient with age is tedious and requires to include one single interaction term between income and age at a time (see Norton et al., 2004, and the Inteff Stata command). Having this limitation in mind, we implement the test and find that the gradient is stable with age above 2 . 


\section{The role of specific health problems}

The previous section demonstrated that there is no gradient in general health in early childhood, that this gradient emerges between birth and age 2 and remains stable from then on. We now turn to the role of specific health problems in the gradient in general health.

The gradient in general health can be explained by the prevalence and severity of some specific health problems, such as chronic conditions (Case et al., 2002). First, low-income children may be more likely to have specific health problems than high-income children (prevalence effect). Second, even if low-income children are not more likely to get specific health problems, the specific health problems they get may be more severe, compared to high-income children (severity effect). Equivalently, income may buffer the negative consequences of specific health problems.

We assess the importance of the prevalence effect using a series of linear probability models:

$$
S_{i, t}=\alpha_{0}+\alpha_{1} \operatorname{Ln}(\text { average income })_{i}+X_{i, t} \delta^{S}+\epsilon_{i, t}^{S}
$$

where $S$ indicates that the child has a specific health problem. The prevalence effect is captured by the coefficient $\alpha_{1}$, which indicates whether poorer children are more likely to obtain specific health problems or not.

The importance of the severity effect is assessed by the following model:

$$
G_{i, t}=\phi_{0}+\phi_{1} \operatorname{Ln}(\text { average income })_{i}+\phi_{2} S_{i, t}+\phi_{3} L n(\text { average income })_{i} \times S_{i, t}+X_{i, t} \delta^{G}+\epsilon_{i, t}^{G}
$$

where $G$ indicates that the child is in good general health. The severity effect is given by the coefficient $\phi_{3}$ : if $\phi_{3}$ is positive and significant, income buffers the negative consequences of the specific health problem on general health.

Equations (3) and (4) are estimated separately for the following specific health problems: having any chronic condition, having each chronic condition, Special Educational Needs and ADHD. The equations are also estimated separately for children ages $0-1$ and 2-17, to inspect the evolution of the prevalence and severity effects across ages.

We begin by examining whether there are income gradients in specific health problems. 
Estimation results for equation (3) are presented in Table 4. The estimates of $\alpha_{1}$ for children ages $0-1$ indicate that income is not related to the probability of having chronic conditions for infants. In contrast, the estimates for children ages 2-17 suggest a strong negative correlation between income and the probability of having any chronic condition, chest, breathing problem, asthma, Special Educational Needs and ADHD. There is one exception though: learning difficulties are more common among high-income children. Our findings are broadly consistent with the absence or smallness of the gradient in general health for infants and its strength for children above 2 .

[Insert Table 4 here]

Table 5 shows estimation results for the severity effect from equation (4). For children ages $0-1$, the estimates of $\phi_{1}$ are not significant, which means that among children with chronic conditions, children from poorer families are not in poorer general health than their wealthier counterparts. The estimates of $\phi_{2}$ for young children shows that having any condition is negatively correlated with general health. Finally, $\phi_{3}$ is generally not significant, which implies that specific health problems are generally as severe for low and high-income infants.

We then inspect the results concerning children above 2, in Table 5. For every specific health problem, the estimates of $\phi_{1}$ are positive and significant, which implies that among children with any of the specific problems, children from richer families are in better general health. A number of estimates of $\phi_{2}$ are negative and significant, suggesting that specific health problems have a negative impact on general health. Finally, the interaction terms between income and the specific health problems, $\phi_{3}$, are positive and significant, for having at least one condition and hearing problems. These results support the hypothesis that family income buffers children from the detrimental effects of these specific problems and that low-income children do not deal with these specific health problems as effectively as high-income children.

\section{[Insert Table 5 here]}

Taken together, the results from Tables 4 and 5 indicate that there is neither a prevalence effect nor a severity effect for infants and both a prevalence and a severity effect for children above 2. These findings are consistent with the absence of any gradient in general health for children ages 0-1 and with the existence of a gradient for children above 
2. These results also suggest that the emergence of the gradient in general health in early childhood could be due to the appearance of a prevalence and a severity effect of specific health problems. From a policy perspective, our findings imply that policies aimed at reducing social health inequalities in childhood should address the reasons why low-income children are more likely to obtain specific health problems and why these specific problems are more severe for them. In particular, reducing gaps in access to palliative medical care may decrease the severity of specific problems for low-income children (Currie and Stabile, 2003).

So far, the prevalence and severity effects have been estimated using static models, which quantify the impact of income on the current probability of having a specific health problem and the effect of current specific problems on current general health. Following Currie and Stabile (2003) and Condliffe and Link (2008), we can exploit the longitudinal nature of the FACS data to examine the effect of income on the emergence of new specific problems and the effect of past specific problems on current general health, using dynamic models. However, the implementation of these models implies a decrease in the sample size (less than 51,000 observations). With this limitation in mind, we re-estimate equation (3), replacing the probability of having a specific health problem at date $t$ with the probability of getting a new specific health problem between $t-1$ and $t$, and equation (4), replacing current specific health problem evaluated at date $t$ with past specific health problem at $t-1$. The results indicate that at ages $2-17$, poorer children are not more likely to get new specific problems, with the exception of difficulty in hearing. However, income has a protective role against the negative consequences of having any chronic condition, difficulty in hearing, skin problems and Special Educational Needs.

\section{How does family income translate into child health?}

In this section, we exploit the large sample size of our data to provide evidence on the roles of housing conditions, nutrition and outfit as channels through which family income translates into child general health. We use information on the number of housing problems (going from "zero" to "four or more"), on whether the family has meat or fish every other day, a roast meat joint at least once a week, fresh vegetables on most days, fresh fruits on most days, and on whether the child has a weatherproof coat and two pairs of allweather shoes. These variables are not available in every wave of the FACS, which leads 
us to examine their role for a subsample of the FACS. Fruit and vegetable consumption and coat and shoes ownership are highly correlated and cannot be included in the same models.

Table 6 contains the results of linear probability models of child general health. The set of controls "controls 3" is included in all the regressions. Models in columns (1), (3) and (6) are estimated using the subsamples in which housing conditions, nutrition and outfit variables have non-missing values, but they do not include controls for housing conditions, nutrition and outfit. Models in columns (2), (4), (5), (7) and (8) are estimated using the same subsamples but they include the variables of interest. The comparison of the coefficient on income in columns (1) and (2) (resp. (3) and (4), etc) indicates whether housing problems are (resp. nutrition or outfit is) an important channel through which income translates into child general health.

Housing problems, nutrition and outfit are not important channels through which family income influences child health. Indeed, Table 6 indicates that the coefficient on income remains highly significant, even if it slightly decreases, when housing problems, nutrition and outfit are included.

The table contains some important results from a policy perspective. Housing problems are negatively related to child health and increases in the number of housing problems are detrimental to child health. In addition, children who eat vegetables or fruits on a regular basis are healthier than those who do not. There is no independent effect of the other nutrition variables on child health. Finally, there is a positive and significant impact of weatherproof coat and all-weather shoes ownership on child health.

[Insert Table 6 here]

\section{Conclusion}

Previous studies on the gradient in childhood in the UK have produced mixed findings regarding the existence of a causal effect of family income on child general health and its evolution with child age. In this paper, we undertake a comprehensive examination of the effect of family income on child general health in the UK, using the FACS. As far as we are aware, this paper is the first to use such a large dataset to shed light on the gradient in childhood in the UK. The data enables us to take a closer look at the age-profile of the gradient than the previous literature, to address the endogeneity of income and to 
examine the role of specific health problems in the gradient in general health.

Our findings indicate that there is no correlation between family income and child general health for infants, that the correlation becomes significant around age 2 and remains stable from 2 to 17 . These results contrast with previous findings, that indicate an increase of the gradient with age. Furthermore, these correlations probably reflect a causal impact of family income on child health. in addition, specific health problems play a role in the gradient in general health. Taken together, these results suggest that income is an important factor in explaining child health in the UK. Finally, we provide some evidence that housing conditions, nutrition and outfit have an independent impact on child general health.

A priority for future research is to investigate the role of child health in the intergenerational transmission of socioeconomic status, in the UK. Indeed, this paper suggests that parental income is an important determinant of child health, and child health is associated with health capital accumulation in childhood and socioeconomic status in adulthood (Currie, 2008). It thus seems important to know whether child health is one of the reasons underlying the intergenerational transmission of socioeconomic status.

Future research could also identify the mechanisms that explain the differences in the gradient between countries. Case et al. (2002) and Currie and Stabile (2003) prove that there is a gradient that increases with child age in the US and Canada. In contrast, Reinhold and Jurges (2011) show that the gradient does not steepen with age in Germany. Finally, our paper demonstrates that the gradient is stable across childhood years in the UK. It is an open question whether these differences in the evolution of the gradient with age are related to differences in national health care systems or other country-specific features. 


\section{References}

Adler, N. E., Boyce, T., Chesney, M. A., Cohen, S., Folkman, S., Kahn, R. L., Syme, S. L., 1994. Socioeconomic status and health: trhe challenge of the gradient. American Psychologist 49(1), 15-24.

Ai, C., Norton, E. C., 2003. Interaction terms in logit and probit models. Economics Letters 80(1), 123-129.

Blaxter, M., 1989. A comparison of measures of inequality in morbidity. In J. Fox (Ed.), Health Inequalities in European Countries. Aldershot: Gower.

Blaxter, M., 1990. Health and Lifestyles. London: Routledge.

Burgess, S., Propper, C., Rigg, J., 2004. The impact of low income on child health: evidence from the ALSPAC Birth Cohort Study. CMPO Working Paper Series No. $04 / 98$.

Case, A., Lee, D., Paxson, C., 2008. The income gradient in children's health: a comment on Currie, Shields and Wheatley Price. Journal of Health Economics 27(3), 801-807.

Case, A., Lubotsky, D., Paxson, C., 2002. Economic status and health in childhood: the origins of the gradient. American Economic Review 92(5), 1308-1344.

Condliffe, S., Link, C. R., 2008. The relationship between economics status and child health: evidence from the United States. American Economic Review 98(4), 16051618.

Currie, J., 2008. Healthy, wealthy and wise: socio-economic status, poor health in childhood, and human capital development. NBER Working Paper No. 13897.

Currie, J., Lin, W., 2007. Chipping away at health: more on the relationship between income and child health. Health Affairs 26(2), 331-344.

Currie, A., Shields, M. A., Price, S. W., 2007. The child health/family income gradient: evidence from England. Journal of Health Economics 26(2), 213-232.

Currie, J., Stabile, M., 2003. Socioeconomic status and child health: why is the relationship stronger for older children. American Economic Review 93(5), 1813-1823.

Deaton, A., Paxson, C., 1998. Aging and inequality in income and health. American Economic Review Paper and Proceedings 88, 248253.

Deaton, A., Paxson, C., 1999. Mortality, education, income, and inequality among American cohorts. NBER Working Paper No. W7140.

Khanam, R., Nghiem, H. S., Connelly, L. B., 2009. Child health and the income gradient: evidence from Australia. Journal of Health Economics 28, 805-817.

Kruk, K. E., 2010. Parental income and the dynamics of health inequality in early childhood. Evidence from the United Kingdom. Working paper available on the 2010 EALE conference website. 
Marmot, M., Bobak, M., 2000. International comparators and poverty and health in Europe. British Medical Journal 321, 1124-1128.

Norton, E. C., Wang H., Ai, C., 2004. Computing interaction effects and standard errors in logit and probit models. Stata Journal 4(2), 154-167.

Propper, C., Rigg, J., Burgess, S., 2007. Child health: evidence on the roles of family income and maternal mental health from a UK birth cohort. Health Economics 16(11), 1245-1269.

Van Doorslaer, E., Wagstaff, A., Bleichrodt, H., Calonge, S., Gerdtham, U., Gerfin, M., Geurts, J., Gross, L., Hakkinen, U., Leu, R.E., O'Donell, O., Propper, C., Puffer, F., Rodriguez, M., Sundberg, G., Winkelhake, O., 1997. Income-related inequalities in health: some international comparisons. Journal of Health Economics 16(1), 93-112.

West, P., 1997. Health inequalities in the early years: is there equalization in youth? Social Science and Medicine 44(6), 833-58.

West, P., Sweeting, H., 2004. Evidence on equalisation in health in youth from the West of Scotland. Social Science and Medicine 59, 13-27.

Wilkinson, R., Marmot, M. (Eds.), 2003. Social determinants of health: the solid facts, 2nd ed. World Health Organisation.

Winkleby, M. A., Jatulis, D. E., Frank, E., Fortmann, S. P., 1992. Socioeconomic status and health: how education, income, and occupation contribute to risk factors for cardiovascular disease. American Journal of Public Health 82, 816-820. 
Figure 1: The child general health/income gradient at each age
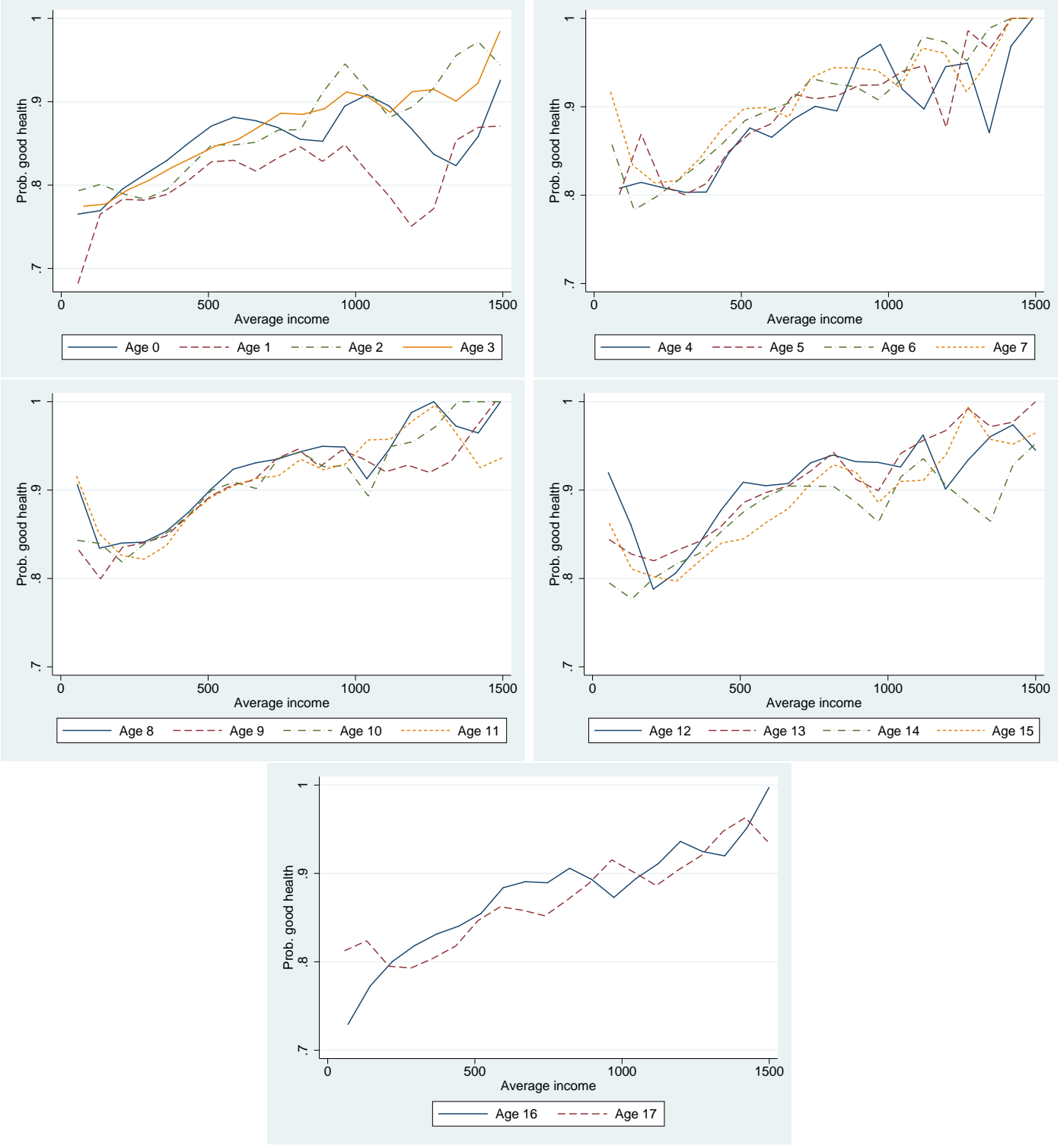
Figure 2: The child general health/income gradient at each age (linear probability models) Panel A. "Controls 1" included.

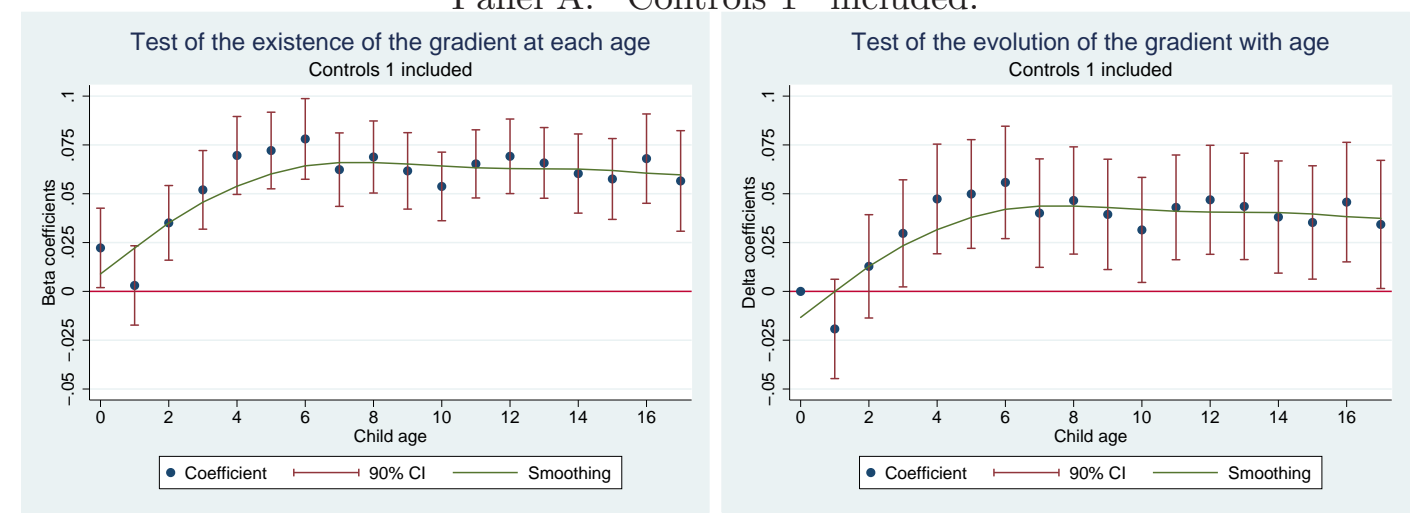

Panel B. "Controls 2" included.
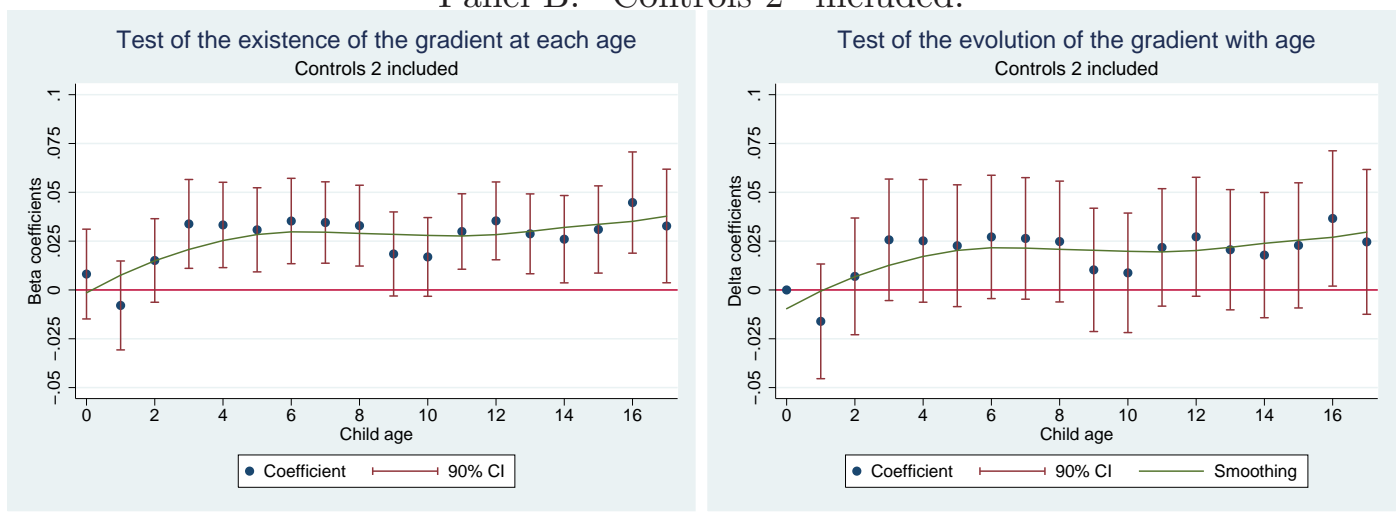

Panel C. "Controls 2" included, nine age groups.
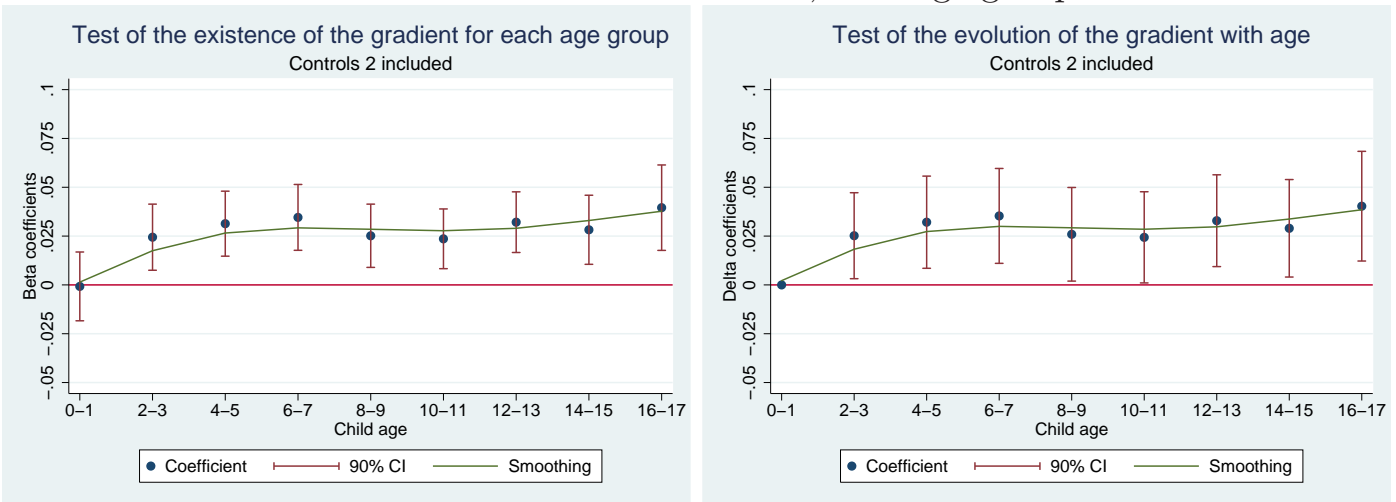

Notes: "Controls 1" include the child gender, age, the presence of the mother and father in the household, the ethnicity of the respondent and the logarithm of household size. "Controls 2" include "controls 1" plus interaction terms between the mother and father presence in the household and their education level and employment status.

78,541 observations. 
Figure 3: The child general health/income gradient at each age, when there is no reverse causation (linear probability models)

Panel A: "Controls 2" included, no reverse causation.
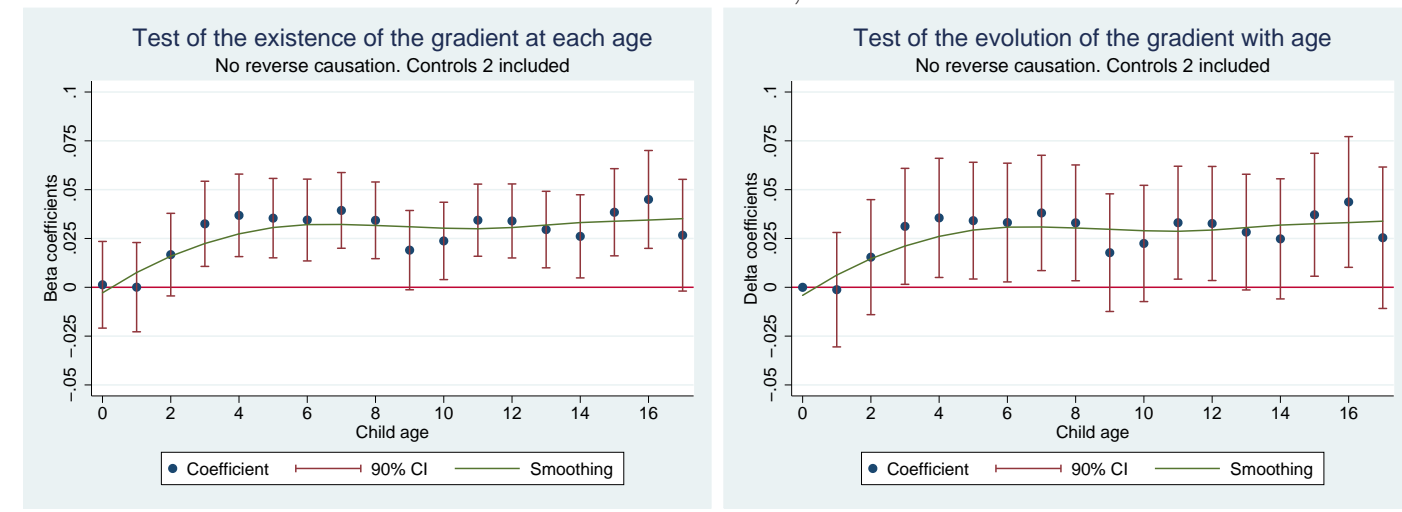

Panel B: "Controls 2" included, no reverse causation, nine age groups.
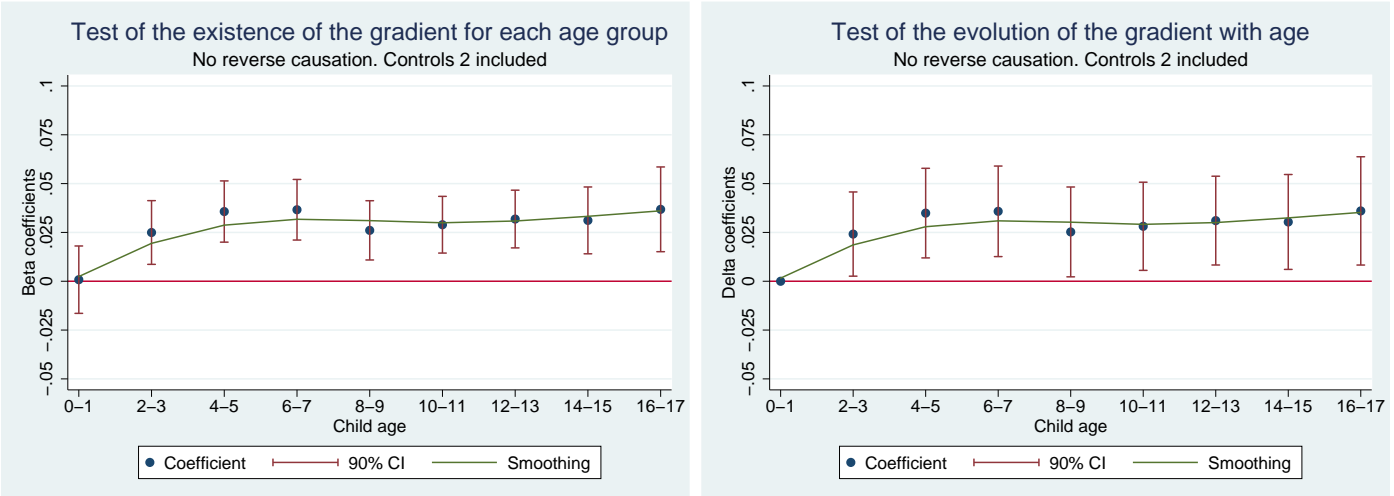

Notes: "Controls 2" include "controls 1" plus interaction terms between the mother and father presence in the household and their education level and employment status. 67,920 observations. 
Figure 4: The child general health/income gradient at each age, when there is no reverse causation and when additional controls are included (linear probability models)

Panel A: "Controls 3" included, no reverse causation.
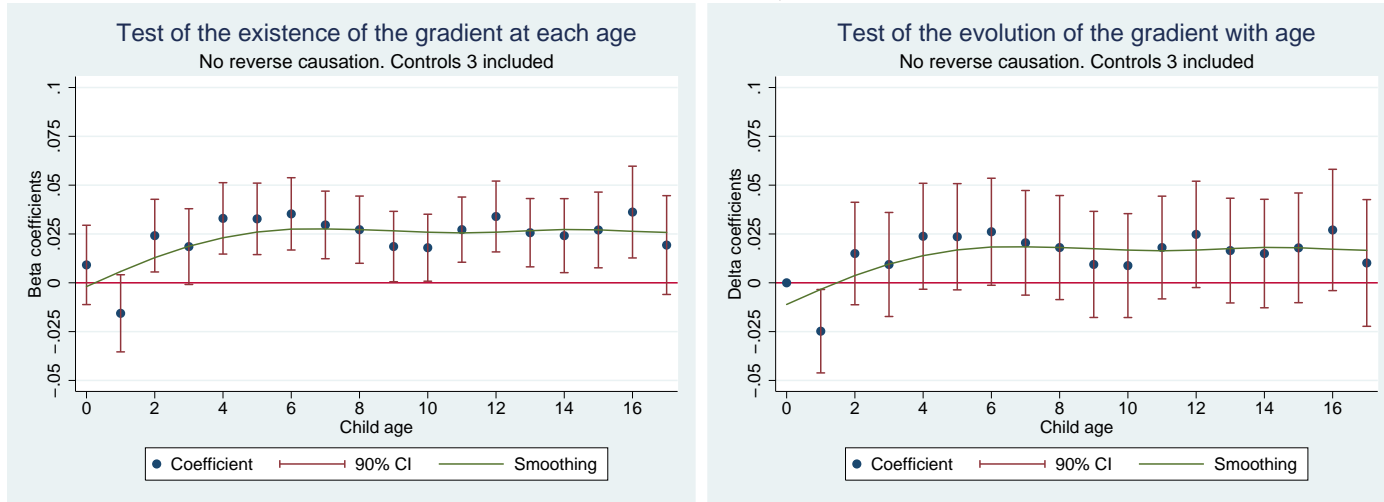

Panel B: "Controls 3" included, no reverse causation, nine age groups.
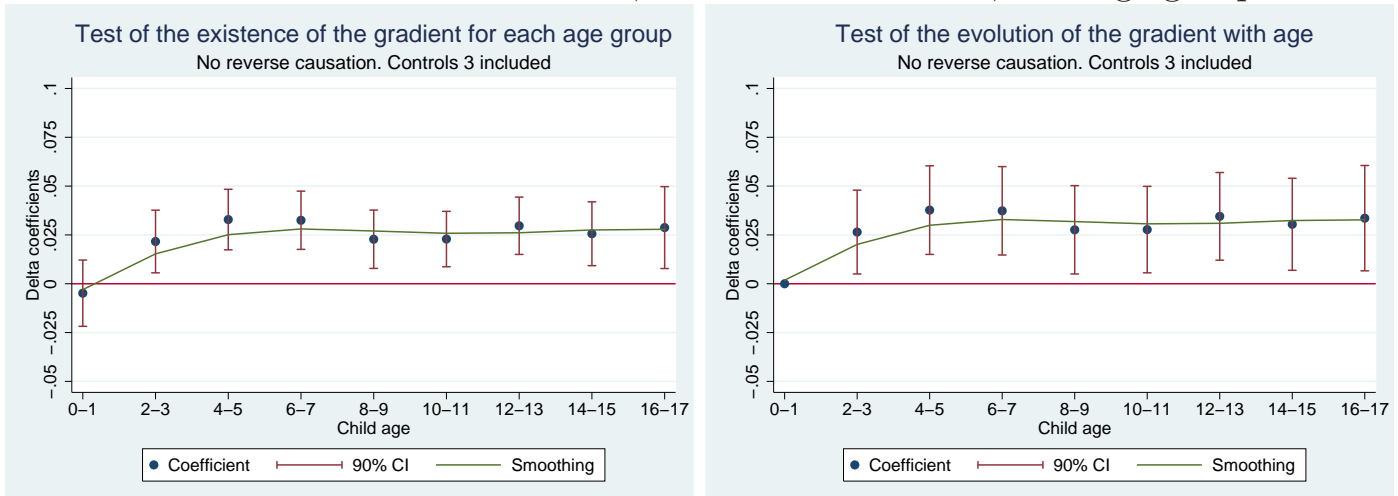

Notes: "Controls 3" include "controls 2" plus regions and the mother's health. 67,920 observations. 
Table 1: Comparison of the FACS with the data used in the previous literature on the gradient in childhood in the UK

\begin{tabular}{|c|c|c|c|c|c|}
\hline Reference & This paper & Currie et al. (2007) & Case et al. (2008) & Kruk (2010) & Propper et al. (2007) \\
\hline Data & FACS & \multicolumn{2}{|c|}{ HSE } & MCS & ALSPAC \\
\hline Nature & Longitudinal & \multicolumn{2}{|c|}{ Cross-sectional } & Cohort & Cohort \\
\hline Year & 2001-2008 & $1997-2002$ & $1997-2005$ & $\begin{array}{c}3 \text { waves: } \\
\text { 2001-03, 2003-05, } 2006\end{array}$ & $\begin{array}{c}\text { Chil observed at } \\
6,18,30 \text { and } 81 \text { months }\end{array}$ \\
\hline No. observations & 78,541 or less & 13,745 & 19,567 & & \\
\hline No. children & & 13,745 & 19,567 & $12,000-13,000$ & 10,000 or less \\
\hline Child age & $0-17$ & \multicolumn{2}{|c|}{$0-15$} & $0-6$ & $0-7$ \\
\hline Child general health & $\begin{array}{c}\text { Available } \\
\text { Assessed by parents }\end{array}$ & \multicolumn{2}{|c|}{$\begin{array}{l}\text { Available } \\
\text { Assessed by parents at ages } 0-12 \\
\text { and by child at ages } 13-15\end{array}$} & $\begin{array}{l}\text { Available in wave } 3 \\
\text { Assessed by mother }\end{array}$ & Available \\
\hline Current income & Exact level & \multicolumn{2}{|c|}{32 brackets } & Brackets & $\begin{array}{l}\text { Financial hardship } \\
+ \text { income in brackets }\end{array}$ \\
\hline Average income & Computed & \multicolumn{2}{|c|}{ Not available } & Computed & $\begin{array}{l}\text { No. of times in financial } \\
\text { hardship since birth }\end{array}$ \\
\hline
\end{tabular}


Table 2: Summary statistics for the variables of interest

\begin{tabular}{lcc}
\hline & $(1)$ & $(2)$ \\
& Mean & Standard de \\
\hline Child general health & & \\
Good & .858 & .348 \\
Child specific health problems & & \\
& & \\
Child chronic conditions & & \\
& & 0.358 \\
Any chronic condition & 0.151 & 0.108 \\
Problem with arms, legs, hands & 0.011 & 0.081 \\
Difficulty in seeing & 0.006 & 0.082 \\
Difficulty in hearing & 0.006 & 0.162 \\
Skin conditions, allergies & 0.027 & 0.250 \\
Chest, breathing problem, asthma & 0.066 & 0.072 \\
Heart, blood pressure & 0.005 & 0.100 \\
Stomach, liver, kidney or digestive problems & 0.010 & 0.131 \\
Learning difficulties & 0.017 &
\end{tabular}

Child Special Educational Needs and ADHD

Special Educational Needs $\quad$ 108

.310

ADHD

.156

Family weekly income

$\operatorname{Ln}($ average income)

.508

Child characteristics

Female

Household characteristics

Ln(family size)

Mother in the household

0.990

0.102

Father in the household

0.754

0.431

Respondent not white

0.081

0.273

Parents' age (interacted with their presence in the household)

Mother's age

36.30

8.073

Father's age

29.68

18.48

Parents' age when they left full time education (interacted with their presence in the household) 
Mother: 16 years old or less

Ref

Mother: 17-18 years old

0.284

0.451

Mother: 19 years old or more

0.219

0.414

Father: 16 years old or less

Ref

Father: 17-18 years old

0.106

0.307

Father: 19 years old or more

0.131

0.338

Father Education Missing

0.226

0.418

Parents' job market status (interacted with their presence in the household)

Mother employed
0.638
0.480

Father employed

0.684

0.465

Mother's general health (interacted with her presence in the household)

Not good

0.086

0.282

Fairly good

0.209

0.406

Good

Ref

Mother's chronic health conditions (interacted with her presence in the household)

Problem with arms, legs, hands

0.0652

0.247

Difficulty in seeing

0.004

0.068

Difficulty in hearing

0.006

0.081

Skin conditions, allergies

0.012

0.112

Chest, breathing problem, asthma

0.046

0.210

Heart, blood pressure

0.020

0.143

Stomach, liver, kidney or digestive problems

0.021

0.143

Diabetes

0.009

0.096

Depression, bad nerves

0.034

0.183

Mental illness

0.011

0.108

Learning difficulties

0.001

0.033

Epilepsy

0.004

0.069

Other health problems

0.037

0.190

Mother smoking status (interacted with her presence in the household)

Smoking

0.293

0.190 
Table 3: The child general health/income gradient, when there is no reverse causation and when additional controls are included (linear probability models)

\begin{tabular}{|c|c|c|c|c|}
\hline & (1) & $(2)$ & $(3)$ & $(4)$ \\
\hline Reverse Causation? & Yes & No & No & No \\
\hline Controls & "Controls 2" & "Controls 2" & $\begin{array}{c}\text { "Controls 3" } \\
=\text { "Controls 2" } \\
\text { + Regions } \\
\text { + Mother's health }\end{array}$ & $\begin{array}{c}\text { "Controls 4" } \\
=\text { "Controls 3" } \\
+ \text { Father's health }\end{array}$ \\
\hline Ln(average inc) & $\begin{array}{l}0.0260 * * * \\
(0.00432)\end{array}$ & $\begin{array}{l}0.0283^{* * *} \\
(0.00405)\end{array}$ & $\begin{array}{l}0.0235^{* * *} \\
(0.00388)\end{array}$ & $\begin{array}{l}0.0219^{* * *} \\
(0.00540)\end{array}$ \\
\hline \multicolumn{5}{|c|}{ Mother's health (interacted with her presence in the household) } \\
\hline Not good & & & $\begin{array}{c}-0.0970^{* * *} \\
(0.00758)\end{array}$ & $\begin{array}{c}-0.0978^{* * *} \\
(0.00921)\end{array}$ \\
\hline Fairly good & & & $\begin{array}{c}-0.113^{* * *} \\
(0.00436)\end{array}$ & $\begin{array}{c}-0.110^{* * *} \\
(0.00538)\end{array}$ \\
\hline Good & & & Ref & Ref \\
\hline Problem with arms, legs, hands & & & $\begin{array}{c}-0.0184^{* *} \\
(0.00811)\end{array}$ & $\begin{array}{l}-0.00964 \\
(0.00967)\end{array}$ \\
\hline Difficulty in seeing & & & $\begin{array}{l}0.00443 \\
(0.0258)\end{array}$ & $\begin{array}{c}0.00287 \\
(0.0293)\end{array}$ \\
\hline Difficulty in hearing & & & $\begin{array}{l}-0.0191 \\
(0.0225)\end{array}$ & $\begin{array}{c}-0.0310 \\
(0.0290)\end{array}$ \\
\hline Skin conditions, allergies & & & $\begin{array}{c}-0.0355^{* *} \\
(0.0180)\end{array}$ & $\begin{array}{l}-0.0161 \\
(0.0216)\end{array}$ \\
\hline Chest, breathing problem, asthma & & & $\begin{array}{c}-0.0388^{* * *} * \\
(0.00961)\end{array}$ & $\begin{array}{c}-0.0298^{* *} \\
(0.0117)\end{array}$ \\
\hline Heart, blood pressure & & & $\begin{array}{l}-0.0172 \\
(0.0138)\end{array}$ & $\begin{array}{c}-0.0272^{*} \\
(0.0165)\end{array}$ \\
\hline Stomach, liver, kidney or digestive problems & & & $\begin{array}{c}-0.0265^{*} \\
(0.0138)\end{array}$ & $\begin{array}{l}-0.0221 \\
(0.0169)\end{array}$ \\
\hline Diabetes & & & $\begin{array}{l}-0.0115 \\
(0.0190)\end{array}$ & $\begin{array}{l}0.00988 \\
(0.0246)\end{array}$ \\
\hline Depression, bad nerves & & & $\begin{array}{c}-0.0408^{* * *} \\
(0.0120)\end{array}$ & $\begin{array}{c}-0.0446^{* * *} \\
(0.0140)\end{array}$ \\
\hline Mental illness & & & $\begin{array}{l}-0.0123 \\
(0.0198)\end{array}$ & $\begin{array}{c}-0.0211 \\
(0.0230)\end{array}$ \\
\hline Learning difficulties & & & $\begin{array}{c}-0.0408 \\
(0.0947)\end{array}$ & $\begin{array}{l}-0.117 \\
(0.118)\end{array}$ \\
\hline Epilepsy & & & $\begin{array}{l}-0.0399 \\
(0.0307)\end{array}$ & $\begin{array}{l}-0.0189 \\
(0.0371)\end{array}$ \\
\hline Other health problems & & & $\begin{array}{l}-0.0169^{*} \\
(0.00970)\end{array}$ & $\begin{array}{c}-0.00516 \\
(0.0115)\end{array}$ \\
\hline Smoking & & & $\begin{array}{c}0.00234 \\
(0.00389)\end{array}$ & $\begin{array}{c}0.0139^{* * *} \\
(0.00467)\end{array}$ \\
\hline Father's health (interacted with his presence & the household & & & \\
\hline Not good & & & & $\begin{array}{c}-0.0348^{* * *} \\
(0.0113)\end{array}$ \\
\hline Fairly good & & & & $\begin{array}{c}-0.0317^{* * *} \\
(0.00563)\end{array}$ \\
\hline $\begin{array}{l}\text { Good } \\
\text { Problem with arms, legs, hands }\end{array}$ & & & & $\begin{array}{c}\text { Ref } \\
-0.00585 \\
(0.00919)\end{array}$ \\
\hline
\end{tabular}


Difficulty in seeing

Difficulty in hearing

Skin conditions, allergies

Chest, breathing problem, asthma

Heart, blood pressure

Stomach, liver, kidney or digestive problems

Diabetes

Depression, bad nerves

Mental illness

Learning difficulties

Epilepsy

Other health problems

Notes: The models are estimated for children ages $0-17$.

The dependent variable is a dummy for whether the child is in good general health.

"Controls 2" include "controls 1" plus interaction terms between the mother and father presence in the household and their education level and employment status.

"Controls 3" include "controls 2" plus regions and the mother's health variables.

"Controls 4" include "controls 3" plus the father's health variables.

Robust standard errors in parentheses. ${ }^{* * *} \mathrm{p}<0.01,{ }^{* *} \mathrm{p}<0.05,{ }^{*} \mathrm{p}<0.1$ 
Table 4: The effect of income on specific health problems: prevalence effect (linear probability models)

\begin{tabular}{lcc}
\hline & Ages 0-1 & Ages 2-17 \\
Specific health problem $S$ & $\alpha_{1}$ & $\alpha_{1}$ \\
\hline & Chronic conditions. 67,920 observations. & \\
At least one condition & 0.00190 & $-0.00934^{* * *}$ \\
& $(0.00662)$ & $(0.00341)$ \\
Arms, legs, hands & & $-7.02 \mathrm{e}-05$ \\
& & $(0.000855)$ \\
Seeing & & -0.000689 \\
& & $(0.000702)$ \\
Hearing & & -0.00121 \\
& 0.00205 & $(0.000849)$ \\
Skin conditions, allergies & $(0.00386)$ & 0.00154 \\
& -0.00133 & $(0.00163)$ \\
Chest, breathing problem, asthma & $(0.00405)$ & $-0.00691^{* * *}$ \\
& & $(0.00251)$ \\
Heart, blood pressure & & -0.000539 \\
Stomach, liver, kidney or digestive problems & 0.00307 & $(0.000606)$ \\
Learning difficulties & $(0.00220)$ & -0.000245 \\
& & $(0.000857)$ \\
& & $0.00144^{* *}$ \\
& & $(0.000672)$
\end{tabular}

Special Educational Needs and ADHD. 59,405 observations.\#\#

Special Educational Needs

$$
\begin{gathered}
-0.0123^{* * *} \\
(0.00308) \\
-0.00342^{* * *}
\end{gathered}
$$

ADHD

Notes: Regressions are based on the following equation, separately estimated for each specific health problem, and for children ages 0-1 and 2-17:

$$
S_{i, t}=\alpha_{0}+\alpha_{1} \operatorname{Ln}(\text { average income })_{i}+X_{i, t} \delta^{S}+\epsilon_{i, t}^{S}
$$

"Controls 3" included.

\# The prevalence effect of problems with arms, legs, hands, difficulty in seeing, difficulty in hearing, heart, blood pressure problems and learning difficulties cannot be estimated for children ages $0-1$, because they are either too rare or not reported.

\#\# These problems are only reported for children above 4 in the data.

Robust standard errors in parentheses. ${ }^{* * *} \mathrm{p}<0.01,{ }^{* *} \mathrm{p}<0.05,{ }^{*} \mathrm{p}<0.1$ 
Table 5: The effect of income and specific health problems on general health: severity effect (linear probability models)

\begin{tabular}{lcccccc}
\hline & \multicolumn{3}{c}{ Ages 0-1 } & \multicolumn{3}{c}{ Ages 2-17 } \\
\cline { 2 - 7 } Specific health problem $S$ & $\phi_{1}$ & $\phi_{2}$ & $\phi_{3}$ & $\phi_{1}$ & $\phi_{2}$ & $\phi_{3}$ \\
\hline & Chronic conditions. 67,920 observations. & & \\
At least one condition & -0.00566 & $-0.555^{* *}$ & 0.0162 & $0.0200^{* * *}$ & $-0.624^{* * *}$ & $0.0540^{* * *}$ \\
& $(0.00993)$ & $(0.259)$ & $(0.0424)$ & $(0.00343)$ & $(0.0939)$ & $(0.0152)$ \\
Arms, legs, hands & & & & $0.0272^{* * *}$ & $-0.690^{*}$ & 0.0615 \\
& & & & $(0.00401)$ & $(0.374)$ & $(0.0598)$ \\
Seeing & & & & $0.0272^{* * *}$ & $-0.785^{*}$ & 0.107 \\
& & & & $(0.00406)$ & $(0.412)$ & $(0.0657)$ \\
Hearing & & & & $0.0267^{* * *}$ & $-0.934^{* * *}$ & $0.104^{*}$ \\
& & & & $(0.00403)$ & $(0.345)$ & $(0.0559)$ \\
Skin conditions, allergies & -0.00299 & 0.460 & $-0.130^{*}$ & $0.0275^{* * *}$ & $-0.331^{*}$ & 0.0177 \\
& $(0.0102)$ & $(0.467)$ & $(0.0750)$ & $(0.00394)$ & $(0.190)$ & $(0.0305)$ \\
Chest, breathing problem & -0.00600 & -0.324 & -0.0461 & $0.0248^{* * *}$ & $-0.391^{* * *}$ & 0.0161 \\
asthma & $(0.0101)$ & $(0.412)$ & $(0.0691)$ & $(0.00371)$ & $(0.142)$ & $(0.0232)$ \\
Heart, blood pressure & & & & $0.0272^{* * *}$ & $-0.987^{* *}$ & 0.130 \\
& & & & $(0.00406)$ & $(0.503)$ & $(0.0810)$ \\
Stomach, liver, kidney & -0.00507 & $-1.238^{*}$ & 0.116 & $0.0272^{* * *}$ & $-0.719 *$ & 0.0453 \\
or digestive problems & $(0.0103)$ & $(0.697)$ & $(0.110)$ & $(0.00396)$ & $(0.411)$ & $(0.0671)$ \\
Learning difficulties & & & & $0.0279 * * *$ & 0.351 & -0.0643 \\
& & & & $(0.00401)$ & $(0.358)$ & $(0.0581)$
\end{tabular}

Special Educational Needs and ADHD. 59,405 observations. \#\#

Special Educational Needs

ADHD

Notes: Regressions are based on the following equation, separately estimated for each specific

$$
G_{i, t}=\phi_{0}+\phi_{1} \operatorname{Ln}(\text { average income })_{i}+\phi_{2} S_{i, t}+\phi_{3} \operatorname{Ln}(\text { average income })_{i} \times S_{i, t}+X_{i, t} \delta^{G}+\epsilon_{i, t}^{G}
$$

"Controls 3" included.

\# The severity effect of problems with arms, legs, hands, difficulty in seeing, difficulty in hearing, heart, blood pressure problems and learning difficulties cannot be estimated for children ages $0-1$ because they are either too rare or not reported.

\#\# These problems are only reported for children above 4 in the data.

Robust standard errors in parentheses. ${ }^{* * *} \mathrm{p}<0.01,{ }^{* *} \mathrm{p}<0.05,{ }^{*} \mathrm{p}<0.1$ 
Table 6: The role of income, housing conditions, nutrition and outfit on child general health (linear probability models)

\begin{tabular}{|c|c|c|c|c|c|c|c|c|}
\hline & (1) & $(2)$ & (3) & (4) & $(5)$ & (6) & (7) & (8) \\
\hline $\operatorname{Ln}($ average inc) & $\begin{array}{l}0.0236^{* * *} \\
(0.00388)\end{array}$ & $\begin{array}{l}0.0212^{* * *} \\
(0.00388)\end{array}$ & $\begin{array}{l}0.0197 * * * \\
(0.00459)\end{array}$ & $\begin{array}{l}0.0188^{* * *} \\
(0.00458)\end{array}$ & $\begin{array}{l}0.0188^{* * *} \\
(0.00458)\end{array}$ & $\begin{array}{l}0.0196 * * * \\
(0.00459)\end{array}$ & $\begin{array}{l}0.0191^{* * *} \\
(0.00459)\end{array}$ & $\begin{array}{l}0.0193 * * * \\
(0.00459)\end{array}$ \\
\hline No. house pbs: 1 & & $\begin{array}{c}-0.0160 * * * \\
(0.00338)\end{array}$ & & & & & & \\
\hline No. house pbs: 2 & & $\begin{array}{c}-0.0248 * * * \\
(0.00507)\end{array}$ & & & & & & \\
\hline No. house pbs: 3 & & $\begin{array}{c}-0.0336 * * * \\
(0.00713)\end{array}$ & & & & & & \\
\hline No. house pbs: $4+$ & & $\begin{array}{c}-0.0500 * * * \\
(0.00875)\end{array}$ & & & & & & \\
\hline Cooked Meal & & & & $\begin{array}{l}0.00715 \\
(0.0109)\end{array}$ & $\begin{array}{c}0.0109 \\
(0.0108)\end{array}$ & & & \\
\hline Meat/Fish & & & & $\begin{array}{c}0.00333 \\
(0.00651)\end{array}$ & $\begin{array}{c}0.00530 \\
(0.00645)\end{array}$ & & & \\
\hline Roast meat & & & & $\begin{array}{l}0.000476 \\
(0.00485)\end{array}$ & $\begin{array}{c}0.00160 \\
(0.00483)\end{array}$ & & & \\
\hline Vegetables & & & & $\begin{array}{l}0.0211^{* * *} \\
(0.00599)\end{array}$ & & & & \\
\hline Fruit & & & & & $\begin{array}{l}0.0158^{* *} \\
(0.00711)\end{array}$ & & & \\
\hline Shoe & & & & & & & $\begin{array}{l}0.0175 * * \\
(0.00870)\end{array}$ & \\
\hline Coat & & & & & & & & $\begin{array}{c}0.0322^{* *} \\
(0.0148)\end{array}$ \\
\hline Observations & 67,400 & 67,400 & 42,306 & 42,306 & 42,306 & 42,312 & 42,312 & 42,312 \\
\hline
\end{tabular}

